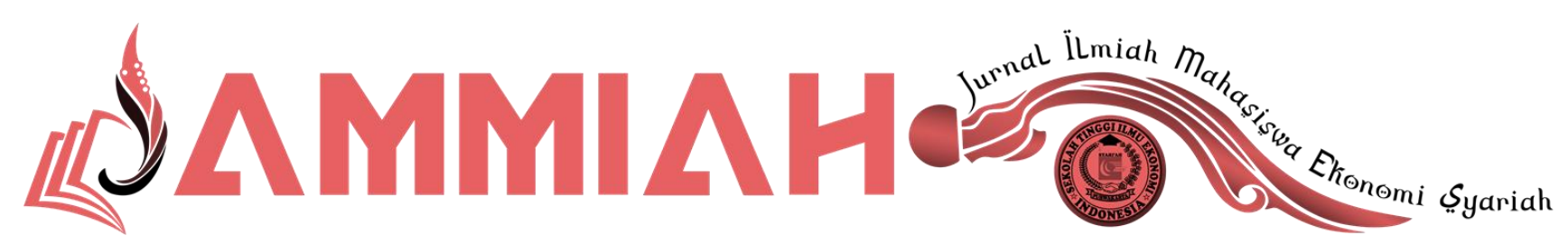

Volume 1 Nomor 1, Maret 2021

DOI: https://doi.org/10.37726/

\title{
Implementasi Etika Bisnis Islam Pada Lembaga Kursus Komputer Di Alego Creative Studio Purwakarta
}

\author{
Ayu Fajar Setiawati \\ PT. Einstrend \\ ayufajar996@gmail.com
}

\begin{abstract}
ABSTRAK
Penelitian ini dilakukan untuk mengetahui Implementasi Etika Bisnis Islam Pada Lembaga Kursus Komputer Di Alego Creative Studio Purwakarta. Penelitian ini juga mengkaji terkait Nilai-nilai etika bisnis, etika bisnis dalam Islam merupakan sesuatu yang penting dan perlu diperhatikan dalam segala aktivitas bisnis atau usaha, karena hal tersebut akan berpotensi menjadi kekuatan dalam perusahaan yang akhirnya akan menjadi stimulus dan berdampak pada loyalitas konsumen terhadap perusahaan itu sendiri. Penelitian ini adalah penelitian lapangan (field research) dan didukung dengan pendekatan kualitatif, bersifat deskriptif kuaitatif yang bertujuan untuk menjelaskan dan menjabarkan Implementasi Etika Bisnis Islam Pada Lembaga Kursus Komputer Di Alego Creative Studio Purwakarta. Hasil penelitian ini menunjuk bahwa nilai-nilai etika bisnis Islam yang diimplementasikan oleh Alego Creative Studio Purwakarta adalah Pertama, nilai kejujuran dalam setiap pelayanan yang diberikan kepada konsumen (murid, siswa, mahasiswa, masyarakat). Kedua, dapat dipercaya tidak mengurangi atau menambah sesuatu dari yang seharusnya atau dari yang telah disepakati. Ketiga, cakap atau cerdas dapat memahami peran dan tanggung jawab bisnisnya dengan baik dan mampu menunjukkan kreatifitas dan inovasi guna mendukung dan mempercepat keberhasilan. Keempat, menyampaikan konteks bisnis dalam bidang edukasi dan mampu mengomunikasikan lembaganya dengan strategi yang tepat.
\end{abstract}


Kata kunci : Etika Bisnis Islam, Nilai-nilai Etika, Lembaga Kursus Komputer.

\section{ABSTRACT}

The study was conducted to see the application of Islamic business ethics at the computer course institute at Alego Creative Studio Purwakarta. This study also examines the values of business ethics, business ethics in Islam is something important and needs to be considered in all business or business activities, because this will be a strength in the company which will eventually become a stimulus and have an impact on consumer loyalty to the company. alone. This research is a field research and is supported by a qualitative, descriptive qualitative approach that aims to explain and describe the implementation of Islamic business ethics at the computer course institute at Alego Creative Studio Purwakarta. The results of this study indicate that the values of Islamic business ethics implemented by Alego Creative Studio Purwakarta are First, the value of honesty in every service provided to consumers (students, students, students, society). Second, it cannot be trusted that it does not reduce or add to something that should have been or what was agreed upon. Third, proficient or intelligent can understand and have good business responsibilities and be able to show creativity and innovation to support and accelerate. Fourth, convey the business context in education and be able to communicate the institution with the right strategy.

Keywords : Islamic Business Ethics, Ethical Values, Computer Course Institute.

\section{PENDAHULUAN}

Islam sebagai sebuah agama yang mempunyai ajaran dan aturan yang sangat komprehensif jelas mengatur segala sesuatu berdasarkan nilai-nilai moralitas. Islam juga senantiasa mengajarkan akan pentingnya nilai-nilai spiritual tanpa meninggalkan nilai-nilai material dalam kehidupan umatnya. Hal itulah yang menjadi satu landasan dasar bahwa umat Islam harus menjadikan keduanya sebagai satu kesatuan dalam meraih tujuan kebahagiaan di dunia dan di akhirat kelak. Dalam hal ini kehadiran Islam bukan untuk diingkari melainkan untuk dipatuhi, Islam tidak mempercayai kehidupan yang hanya berorientasi pada akhirat tanpa memikirkan materi tanpa memikirkan akhirat. ${ }^{1}$

Ekonomi Islam mengarahkan bisnis atau dunia usaha yang penuh dengan nilai-nilai ekonomi dan etika, dengan kata lain bahwa Islam tidak pernah memisahkan ekonomi dengan etika. Islam tidak membedakan antara ekonomi dan etika, sebagaimana juga Islam tidak membedakan antara ilmu dan akhlak, politik

${ }^{1}$ Alma Bukhari, Manajemen Bisnis Syariah, (Bandung: Alfabeta, 2009), 48.

JAMMIAH (Jurnal Ilmiah Mahasiswa Ekonomi Syariah), Volume 1, Nomor 1, Maret 2021

http://journal.sties-purwakarta.ac.id/index.php/jammiah/

ISSN: xxxx-xxxx (Media Online) xxxx-xxxx (Media Cetak) 
dan etika, perang dan etika, dan lain-lain. Sehingga dalam mengarungi kehidupan seorang muslim haruslah memiliki budi pekerti dan akhlak yang mulia, seperti yang di contohkan Nabi Muhammad Saw. Individu muslim maupun kelompok di satu sisi diberi kebebesan untuk mencari keuntungan sebesar-besarnya tetapi di lain sisi dia terikat dengan iman dan etika sehingga dia tidak bebas mutlak dalam permasalahan ekonomi untuk menginvestasikan modalnya atau membelanjakan hartanya yang akan dapat merugikan orang lain. Masyarakat muslim juga tidak bebas tanpa kendali dalam memproduksi segala sumber daya alam yang dapat berakibat merusak. Dia terikat dengan ikatan akidah dan etika mulia disamping juga dengan hukum Islam. ${ }^{2}$

Penelitian tentang Implementasi Etika Bisnis Islam sudah banyak dilakukan oleh peneliti sebelum nya seperti yang dilakukan oleh Elida Elfi Barus, Nuriani Nuriani $^{3}$, Islam menghalalkan jual-beli yang termasuk juga bisnis. Namun, tentu saja sebagaimana seharusnya seorang muslim berusaha dalam dunia bisnis agar mendapatkan berkah dari Allah SWT di dunia maupun di akhirat. Aturan bisnis Islam menjelaskan berbagai hal yang harus dilakukan oleh para pebisnis muslim dan diharapkan bisnis tersebut akan maju dan berkembang lantaran selalu mendapat berkah dari Allah SWT. Etika Bisnis Islam Menjamin, baik pebisnis, mitra bisnis, konsumen masing- masing akan saling mendapatkan keuntungan, namun banyak para pelaku usaha/bisnis yang tidak lagi mementingkan aturan-aturan Islam dalam berbisnis, dalam artian hanya mengejar keuntungan duniawi semata. Mengabaikan etika-etika bisnis yang seharusnya mereka terapkan. Namun demikian, ada satu rumah makan yang hadir dengan konsep bisnis syariah dengan nuansa Islami, yaitu RM Wong Solo. RM Wong Solo menggunakan konsep bisnis berbasis syariah, bagi mereka bekerja adalah jihad. Hal ini dapat dilihat dari beberapa aspek seperti karyawan, kualitas produk dan kepemimpinannya. Dampak yang ditimbulkan pun sangat bagus, terbukti RM Wong Solo sangat diminati pelanggan tidak hanya dalam negeri, tapi juga luar negeri. RM Wong Solo juga mendapat banyak penghargaan dibidang kuliner,. Penelitian ini hanya dilakukan dibidang kuliner tidak di lembaga kursus dan pelatihan. Selanjutnya penelitian dilakukan oleh Leli Rosiyana, Zainul Arifin, Sunarti Sunarti ${ }^{4}$, Bisnis merupakan aktivitas ekonomi yang bertujuan memperoleh keuntungan. Realitas bisnis

2 Alma Bukhari, Manajemen Bisnis Syariah, (Bandung: Alfabeta, 2009), 49.

${ }^{3}$ Barus, Elida Elfi; Nuriani, Nuriani. Implementasi Etika Bisnis Islam (Studi Pada Rumah Makan Wong Solo Medan). Jurnal Perspektif Ekonomi Darussalam, 2016, 2.2: 125-146.

${ }^{4}$ Rosiyana, Leli; Arifin, Zainul; Sunarti, Sunarti. Implementasi Etika Bisnis Islam Guna Membangun Bisnis Yang Islami (Studi pada Waroeng Steak And Shake Cabang Malang). Jurnal Administrasi Bisnis, 2017, 53.1: 196-201.

JAMMIAH (Jurnal Ilmiah Mahasiswa Ekonomi Syariah), Volume 1, Nomor 1, Maret 2021 
menunjukkan ada pelaku bisnis yang mulai mengabaikan aspek moralitas dalam aktivitas bisnis. Pelaku bisnis yang profesional adalah pelaku bisnis yang memperhatikan aspek moralitas dalam setiap aktivitasnya, sebagai acuan dalam menentukan tujuan dan tindakan yang etis, serta menjadi bentuk kepedulian terhadap hak-hak individu. Judul penelitian ini adalah Implemetasi etika bisnis islam guna membangun bisnis yang islami. Setiap aktivitas bisnis tidak boleh mengesampingkan aspek moralitas, etika bisnis yang bermoral erat kaitannya dengan etika bisnis yang dijelaskan dalam agama. Tujuan penelitian ini adalah untuk mengetahui implementasi etika bisnis islam guna membangun bisnis yang islami yang telah diterapkan oleh Waroeng Steak and Shake cabang Malang, serta mengetahui faktor pendukung dan penghambat dalam implementasinya. Penelitian ini juga hanya terfokus pada para pelanggan kuliner saja dan tidak pada dunia pendidikan atau lembaga kursus dan pelatihan.

Penelitian-penelitian sebelumnya banyak mengkaji atau meneliti tentang Implementasi Etika Bisnis Islam di bidang kuliner saja baik untuk pelanggan rumah makan ataupun karyawan rumah makan saja tidak dengan lembaga-lembaga, tempat kursus, ataupun lembaga pelatihan lainnya.

Penelitian ini mengkaji lebih dalam terkait Implementasi Etika Bisnis Islam Pada Lembaga Kursus di Alego Creative Studio Purwakarta termasuk strategi menangani Etika Bisnis yang diterapkan kepada Siswa, Mahasiswa-mahasiswi, Masyarakat dan Umum.

Fokus penelitian ini adalah untuk mengetahui Implementasi Etika Bisnis Islam Pada Lembaga Kursus Komputer Di Alego Creative Studio Purwakarta .

\section{TINJAUAN PUSTAKA}

Penelitian tentang Implementasi Etika Bisnis Islam sudah banyak dilakukan oleh peneliti sebelum nya seperti yang dilakukan oleh Fitri Amalia ${ }^{5}$, Tujuan dari penelitian ini adalah untuk mengetahui bagaimana implementasi etika bisnis Islam bagi para pedagang di Bazaar Madinah Depok. Penelitian ini merupakan jenis penelitian studi kasus dengan metode survei. Penelitian yang dilakukan berupa deskriptif menggunakan studi literatur serta mengambil data primer dalam bentuk pengisian kuesioner dan wawancara. Ada beberapa indikator yang dapat digunakan untuk mengukur etika bisnis Islam, yaitu meliputi empat aspek: prinsip, manajemen, marketing/ iklan dan produk/harga. Adapun yang menjadi responden dalam penelitian ini adalah seluruh pedagang di Bazaar Madinah Depok. Adapun

${ }^{5}$ Amalia, Fitri. Implementasi Etika Bisnis Islam Pada Pedagang Di Bazar Madinah Depok. Prosiding Seminas, 2012, 1.2.

JAMMIAH (Jurnal Ilmiah Mahasiswa Ekonomi Syariah), Volume 1, Nomor 1, Maret 2021

http://journal.sties-purwakarta.ac.id/index.php/jammiah/

ISSN: xxxx-xxxx (Media Online) xxxx-xxxx (Media Cetak) 
perbedaan dari penelitian yang dilakukan oleh peneliti ini adalah lokasi serta tujuan peneliti, para peneliti sebelumnya melakukan penelitian terhadap pedagang pasar serta di lingkungan pasar, sedangkan yang dilakukan oleh peneliti sekarang adalah Implementasi Etika Bisnis Islam pada lembaga kursus Alego Creative Studio di Purwakarta.

Selanjutnya penelitian dilakukan oleh Richa Angkita Mulyawisdawati, 6 Penelitian ini adalah penelitian deskriptif analitik dengan pendekatan kualitatif. Adapun data yang diperoleh merupakan hasil wawancara penulis dengan beberapa stake holder di CV Rumah Warna Yogyakarta serta observasi langsung pada objek. Hasil penelitian menunjukkan bahwa secara keseluruhan CV Rumah Warna Yogyakarta telah mengimplementasikan kelima prinsip etika bisnis dalam Islam, yaitu diantaranya; prinsip tauhid; prinsip keseimbangan; prinsip kehendak bebas; prinsip tanggung jawab serta prinsip kebajikan (ihsan). perbedaan dari penelitian yang dilakukan oleh peneliti ini adalah lokasi serta tujuan peneliti, para peneliti sebelumnya melakukan penelitian di lingkungan CV Rumah Warna atau percetakan, sedangkan yang dilakukan oleh peneliti sekarang adalah Implementasi Etika Bisnis Islam pada lembaga kursus Alego Creative Studio di Purwakarta bukan di pasar dan bukan di percetakan.

Selanjutnya penelitian dilakukan oleh Bayu Kurniawan Dwiatma, ${ }^{7}$ Hasil penelitian ini menunjuk bahwa nilai-nilai etika bisnis Islam yang diimplementasikan oleh PT. Helutrans Al Haadi Ziarah Tour adalah Pertama, nilai kejujuran dalam setiap pelayanan yang diberikan kepada konsumen. Kedua, nilai kerendahan hati dalam melayani konsumen yang berbentuk apresiasi dan kebijakan. Ketiga, nilai menepati janji dalam pelayanan ibadah haji dan umroh dari apa yang telah tertulis dan diucapkan kepada konsumen. Keempat, nilai tanggung jawab dalam setiap pelaksanaan pelayanan kepada konsumen atau jamaah haji dan umroh. Berbeda dengan penelitian-penelitian sebelemnya kali ini penelitian mengenai Etika Bisnis Islam Dalam Pelayanan Haji dan Umroh, sedangkan penelitian yang dilakukan oleh peneliti sekarang adalah Implementasi Etika Bisnis Islam PADA Lembaga Kursus Alego Creative Studio di Purwakarta.

\section{HASIL DAN PEMBAHASAN}

\section{Implementasi Etika Bisnis Islam Pada Lembaga Kursus Komputer Di Alego Creative Studio Purwakarta}

${ }^{6}$ Mulyawisdawati, Richa Angkita. Implementasi Etika Bisnis Islam di CV Rumah Warna Yogyakarta. Ijtihad: Jurnal Hukum dan Ekonomi Islam, 2019, 13.2: 146-167.

${ }^{7}$ Dwiatma, Bayu Kurniawan. Etika Bisnis Islam Dalam Pelayanan Haji Dan Umroh. Bina'al-Ummah, 2019, 14.1: 59-70.

JAMMIAH (Jurnal Ilmiah Mahasiswa Ekonomi Syariah), Volume 1, Nomor 1, Maret 2021

http://journal.sties-purwakarta.ac.id/index.php/jammiah/

ISSN: xxxx-xxxx (Media Online) xxxx-xxxx (Media Cetak) 
Alego Creative Studio bergerak di bidang pembuatan games sejak tahun 2011, pelatihan computer dari tahun 2014 hingga sekarang, Selama praktik kerja lapangan dilaksanakan, penulis ditempatkan pada bagian Umum. Penulis membantu karyawan dalam menyelesaikan tugas khususnya pada pemeriksaan dokumen baik dokumen sekretaris ataupun pembendaharaan. Banyak ilmu yang didapat dari kegiatan-kegiatan yang dilakukan di Alego Creative Studio dengan bimbingan dan arahan dari pimpinan dan dibantu para staff dan instruktur yang selalu bersedia memberikan ilmu kepada penulis dalam melakukan kegiatan praktik kerja lapangan.

Impelentasi etika bisnis islam dalam menjalankan usaha bisnis di bidang Edukasi, Etika adalah cabang filosofi yang menginvestigasi penilaian normatif tentang tingkah laku benar atau salah, mana yang harus dilakukan dan tidak dilakukan. Kebutuhan akan etika timbul dari keinginan untuk menghindari masalah-masalah dikehidupan nyata. Etika tidak membahas isu apa tentang kepercayaan yang seharusnya atau tidak seharusnya dianut, karena sudah menyangkut masalah keagamaan. Etika berhubungan dengan prinsip yang membimbing perilaku manusia. Etika adalah study tentang norma dan nilai-nilai tentang salah dan benar, baik dan buruk, apa yang seharusnya kita lakukan dan dihindari. ${ }^{8}$ Berdasarkan hasil wawancara yang didapatkan bahwa manajemen dalam usaha bisnis diperlukan di Alego Creative Studio. Fungsi manajeman ini sebagai planning, controlling, processing, organizing, actualiting, dan financing. Usaha bisnis di bidang Edukasi sekalipun, harus mempunyai manajemen, agar lebih teratur dan terukur. Karena setiap usaha (bisnis), sudah pasti mau naik kelas, menjadi usaha besar bahkan Lembaga yang berfokus di bidang Edukasi dan perbaikan SDM (Sumber Daya Manusia). Usaha (bisnis) besar, awalnya pasti sebagai usaha (bisnis) kecil yang dimenej dan terus berkembang sehingga menyentuh level usaha (bisnis) besar. Bahwa dalam prinsip-prinsip yang dijalankan dalam pelaksanaan disesuaikan dengan aturan islam atau sesuai dengan ketentuan dalam Al-Qur'an. Bahwa dalam penetapan harga dan pelayanan yang dilakukan disesuaikan dengan aturan islam, dimana dalam pengambilan harga tidak terlalu memberatkan konsumen (murid, siswa, mahasiswa, masyarakat).

Etika bisnis Islam menurut para pelaku bisnis di lembaga kursus Alego Creative Studi yaitu :

a. Prinsip : visi misi sesuai syariat, amal makruf nahi munkar, asas tauhid, kebenaran, keadilan dan amanat.

b. Manajemen : memberi hak kepada murid, siswa, mahasiswa, masyarakat dari sisi kenyamanan, kepercayaan dan kualitas pengajar di lembaga kursus

${ }^{8}$ Achmad Charris Zubair, Kuliah Etika, (Jakarta : Rajawali Press 1995), 13.

JAMMIAH (Jurnal Ilmiah Mahasiswa Ekonomi Syariah), Volume 1, Nomor 1, Maret 2021

http://journal.sties-purwakarta.ac.id/index.php/jammiah/

ISSN: xxxx-xxxx (Media Online) xxxx-xxxx (Media Cetak) 
komputer tersebut dalam mengajar dan menyampaikan suatu ilmu, informasi lengkap, tidak mencampur hal yang halal dan haram, membayar zis, memperhatikan karyawan dan konsumen (siswa, murid, mahasiswa, masyarakat).

c. Marketing atau Iklan atau Promosi : jujur, tanpa penipuan atau pemalsuan informasi, jaminan pelayanan, detail dari suatu lembaga.

d. Harga, menetapkan harga sesuai ekspektasi laba, tidak mengambil untung secara berlebihan.

e. Dapat bermanfaat bagi masyarakat sekitar serta orang-orang yang membutuhkan pelatihan khusus yang di adakan oleh Alego Creative Studio secara gratis.

Kata etika berasal dari kata ethos dalam bahasa Yunani yang berarti kebiasaan (custom) kamus Webster etika adalah distinguishing character, sentiment, moral nature, orguiding beliefs of a person, group, or institution (karakter istimewa, sentiment, tabiat, moral, atau keyakinan yang membimbing seseorang, kelompok atau institusi) $)^{9}$. Pengertian yang lebih tegas makna etika adalah the system the nature of value concepst, good, bad, ought, right, wrong, etc, and of the general principles which justify us inapplying them to anything, alsolled moral philosophy (etika merupakan studi sistematis tentang tabiat konsep nilai, baik, buruk, harus, benar salah, dan lain sebagainya. Prinsip- prinsip umum yang membenarkan kita untuk mengaplikasikannya atas apa saja). ${ }^{10}$

Definisi Etika menurut islam Kata "Akhlak" berasal dari bahasa Arab yang sudah di Indonesiakan yang juga diartikan sebagai perangai dan kesopanan, yang mencakup dengan watak, kesopanan, tingkah laku atau tabiat. Di samping istilah akhlak, juga dikenal dengan istilah etika dan moral. Ketiga istilah itu sama-sama menentukan nilai baik dan buruk sikap dan perbuatan manusia. Perbedaannya terletak pada standar masing-masing. Bagi akhlak standartnya adalah Al-quran Assunnah, bagi etika standartnya adalah pertimbangan akal dan fikiran, dan bagi moral standartnya adalah adat kebiasaan yang umum berlaku di lingkungan masyarakat. Secara umum etika dapat didefinisikan sebagai satu usaha sistematis, dengan menggunakan akal untuk memaknai individu atau sosial kita, pengalaman moral, dimana dengan cara itu dapat menetukan peran yang akan mengatur tindakan manusia dan nilai yang bermanfaat dalam kehidupan. ${ }^{11}$

\footnotetext{
${ }^{9}$ G.Webster, Webster's New Collgiatem Dictionary, (New York : G.C.Merriam Company 1980), 397.

${ }^{10}$ Achmad Charris Zubair, Kuliah Etika, (Jakarta : Rajawali Press 1995), 13.

${ }^{11}$ Abdul Aziz, Etika Bisnis Perspektif Islam, (Bandung : Alfabeta, 2013), 24.
}

JAMMIAH (Jurnal Ilmiah Mahasiswa Ekonomi Syariah), Volume 1, Nomor 1, Maret 2021 
Etika dan ekonomi memiliki keterkaitan yang tak dapat dipisahkan. Dengan demikian, etika yang baik berdampak pada terbangunnya muamalah atau kerjasama ekonomi yang baik. Tapi sistem ekonomi yang berkembang saat ini masih belum bisa menyelesaikan persoalan bangsa dari kemiskinan yang banyak terjadi di Indonesia dan negara berkembang lainnya. Sistem ekonomi saat ini sering terjadi penyuapan, pengemasan yang tidak baik, penekanan pelanggaran, kenaikan harga yang tidak wajar. Segala hal yang berkaitan dengan beberapa permasalahan diatas, yang berkaitan dengan etika dan hukum, termasuk membangun ketidak percayaan di kalangan para konsumen. ${ }^{12}$

Ali Hasan mendefinisikan etika bisnis dalam syari'ah Islam adalah akhlak dalam menjalankan bisnis sesuai dengan nilai-nilai Islam, sehingga dalam melaksanakan bisnisnya tidak perlu ada kekhawatiran, sebab sudah diyakini sebagai sesuatu yang baik dan benar. Oleh sebab itu, secara simplistik etika bisnis Islam yang dimaksud dalam kajian teoritis ini adalah segala sesuatu hal yang berhubungan dengan ekonomi, yang sistem dan regulasi di dalamnya lebih mengedepankan nilai-nilai Islam, serta mengimplementasikan etika (akhlak) dalam setiap bisnis usaha yang dijalani. ${ }^{13}$

Strategi Bisnis yang di jalankan di Alego Creative Studio Purwakarta sesuai dengan syariat Islam, penjelasannya sebagai berikut;

1. Siddiq

Siddiq berarti jujur atau benar, dalam menjalankan bisnisnya, Nabi Muhammad SAW selalu menunjukkan kejujuran dan meyakini betul bahwa membohongi para pelanggan sama dengan mengkhianati mereka. ${ }^{14}$ Begitupun yang dilakukan oleh manajemen di Alego jujur dalam menjalankan bisnis di bidang edukasinya baik dari segi pembiayaan dan pelayanan yang di terima. Tidak mengingkari perjanjian jam belajar serta mata pelajaran yang di terima.

Berikut dalam alquran surat Al- Ahzab (33) : 70-71 yang berbunyi :
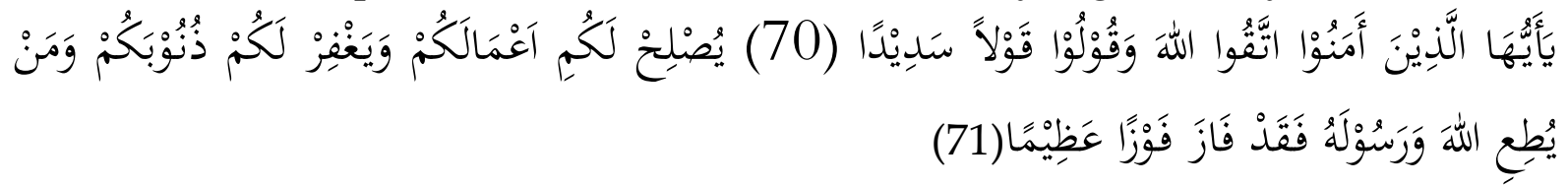

Artinya:

${ }^{12}$ Dewantara, Aditama. Etika Distribusi Ekonomi Islam (Perbandingan Sistem Distribusi Kapitalis Dengan Sistem Distribusi Islam). Ad Deenar: Jurnal Ekonomi Dan Bisnis Islam, 2020, 4.01: 20-36.

${ }^{13}$ Ali Hasan, Manajemen Bisnis Syari"eah Kaya di Dunia Terhormat di Akhirat, (Yogyakarta: Pustakan Pelajar.2009), 171.

${ }^{14}$ Yahya, Aqil Barqi. Etika Bisnis (Perilaku) Bisnis Rasulullah Saw Sebagai Pedoman Berwirausaha. Jurnal Masharif Al-Syariah: Jurnal Ekonomi Dan Perbankan Syariah, 2020, 5.1.

JAMMIAH (Jurnal Ilmiah Mahasiswa Ekonomi Syariah), Volume 1, Nomor 1, Maret 2021 
"Wahai orang-orang yang beriman! Bertakwalah kamu kepada Al;lah dan ucapkanlah perkataan yang benar." niscaya Allah akan memperbaiki amal-amalmu dan mengampuni dosa -dosamu. Dan barang siapa menaati Allah dan Rasul-Nya, maka sungguh dia menang dengan kemenangan yang agung."

Dalam surat Al-Isra (17): 53 juga dijelaskan tentang kejujuran. Bunyi ayatnya adalah:

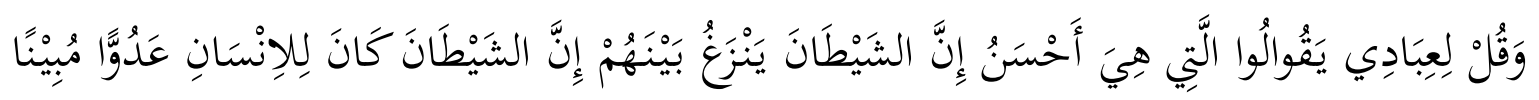

Artinya:

"Dan katakanlah kepada hamba-hamba-Ku hendaklah mereka mengucapkan perkataan yang lebih baik (benar). Sungguh setan itu selalu menimbulkan perselisihan di antara mereka. Sungguh setan adalah musuh yang nyata bagi manusia."

Di atas sudah dijelaskan bahwasanya hendaklah manusia berkata perkataan yang baik lagi benar. Karena dengan perkataan yang baik lagi benar maka, akan terjadi sebuah perdamaian diantara mereka. Tidak hanya dalam al quran saja telah diterangkan banyak masalah jujur, dan berkata baik. Tetapi, dalam hadist Nabi Muhammad SAW juga di jelaskan yang bunyinya:

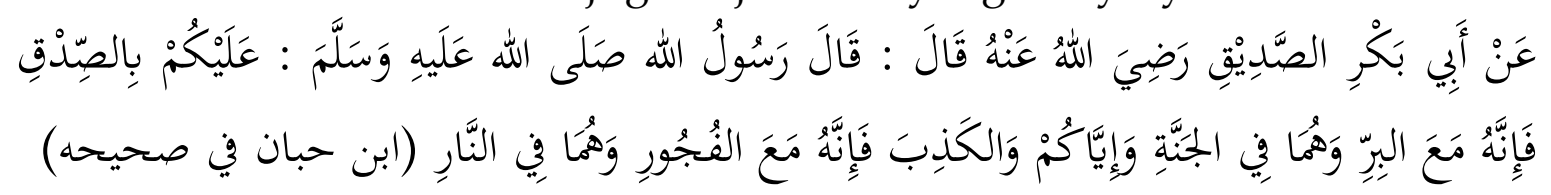

Artinya:

"Dari Abu Bakar As-Shidiq RA ia berkata: Rasulullah SAW bersabda: wajib atasmu berlaku jujur, karena jujur itu bersama kebaikan, dan keduanya di surga. Dan jauhkanlah dirimu dari dusta, karena dusta itu bersama kedurhakaan, dan keduanya di neraka." (HR Ibnu Hibban di dalam shohihnya)

2. Amanah

Amanah berarti - dapat dipercaya. Dalam konteks ini, amanah adalah tidak mengurangi atau menambah sesuatu dari yang seharusnya atau dari yang telah disepakati. Itu bisa terjadi antara penjual dan pembeli, penyewa dan yang menyewakan, Lembaga dan Konsumen. ${ }^{15}$ Contoh kasus misalnya ketika ada murid yang lupa akan pertemuan yang sudah menjadi perjanjian diawal yang seharusnya 10 kali pertemuan akan tetapi murid baru saja melakukan 7 kali pertemuan, manajemen Alego akan mengingatkan kembali kepada murid tersebut agar menyelesaikan studinya di Alego Creative Studio.

${ }^{15}$ Saifullah, Muhammad. Etika Bisnis Islami Dalam Praktek Bisnis Rasulullah. Walisongo: Jurnal Penelitian Sosial Keagamaan, 2011, 19.1: 127-156.

JAMMIAH (Jurnal Ilmiah Mahasiswa Ekonomi Syariah), Volume 1, Nomor 1, Maret 2021 
Dalam hadits Nabi disebutkan:

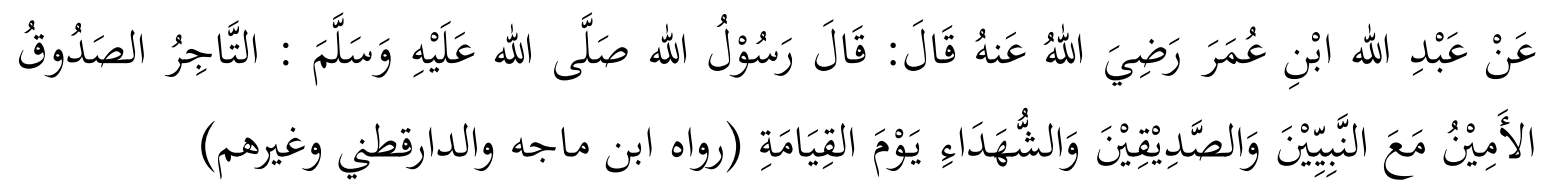

Artinya:

"Dari 'Abdullah bin 'Umar radhiallahu 'anhu bahwa Rasulullah shallallahu 'alaihi wa sallam bersabda: "Seorang pedagang muslim yang jujur dan amanah (terpercaya) akan (dikumpulkan) bersama para Nabi, orang-orang shiddiq dan orang-orang yang mati syahid pada hari kiamat (nanti)."

3. Fatanah

Fațanah berarti cakap atau cerdas. Pembisnis yang cerdas mampu memahami peran dan tanggung jawab bisnisnya dengan baik. Dia pun mampu menunjukkan kreatifitas dan inovasi guna mendukung dan mempercepat keberhasilan pada lembaganya. ${ }^{16}$ Alego Creative Studio terus berkembang dan berinovasi dari waktu ke waktu, dari mulai merintis hingga sekarang yang tadinya hanya studio pembuatan games, sekarang menjadi lembaga kursus Komputer satu-satunya di Purwakarta yang memiliki tarif yang masih sangat terjangkau di banding tempat kursus computer lain dengan tenaga pengajar yang berkualitas pada bidangnya.

4. Tabligh

Secara bahasa, tabligh bisa dimaknai dengan menyampaikan. Dalam konteks bisnis dalam dunia edukasi, pemahaman tabligh bisa mencakup argumentasi dan komunikasi. Penjual hendaknya mampu mengomunikasikan lembaganya dengan strategi yang tepat. Dengan sifat tabligh, seorang pembisnis diharapkan mampu menyampaikan keunggulankeunggulan lembaganya dengan menarik dan tepat sasaran tanpa meninggalkan kejujuran dan kebenaran (transparency and fairness). Dengan itu, pelanggan dapat dengan mudah memahami pesan bisnis yang disampaikan. ${ }^{17}$

Alego juga melakukan pelatihan edukasi pembinaan gratis kepada para staff tanpa membebani biaya kepada para staff dan memiliki salah satu mimpi yang ingin di capai, mimpi ini adalah mengadakan pelatihan gratis dengan tetap

\footnotetext{
${ }^{16}$ Gusriani, Raden Yani; Faulidi, Haris. Dakwah Dalam Bisnis Dan Enterpreneur Nabi Muhammad SAW. Alhadharah: Jurnal Ilmu Dakwah, 2017, 11.21.

${ }^{17}$ Mardasari, Leka Ayu. Strategi Pemasaran Dalam Pengembangan Usaha Pada Konveksi Wijaya Di Desa Botoran Tulungagung Perspektif Ekonomi Islam. Eksyar: Jurnal Ekonomi Syari'ah \& Bisnis Islam, 2020, 7.02: 109-131.
}

JAMMIAH (Jurnal Ilmiah Mahasiswa Ekonomi Syariah), Volume 1, Nomor 1, Maret 2021 
membayar gaji karyawan tanpa ada income, inilah salah satu goalnya Alego Creative Studio di Purwakarta sebagai lembaga kursus yang mencoba mengimplementasikan etika bisnis islam pada lembaga kursus computer di Alego Creative Studio Purwakarta.

\section{KESIMPULAN}

Hasil penelitian ini menunjuk bahwa nilai-nilai etika bisnis Islam yang diimplementasikan oleh Alego Creative Studio Purwakarta adalah Pertama, nilai kejujuran dalam setiap pelayanan yang diberikan kepada konsumen (murid, siswa, mahasiswa, masyarakat). Kedua, dapat dipercaya tidak mengurangi atau menambah sesuatu dari yang seharusnya atau dari yang telah disepakati. Ketiga, cakap atau cerdas dapat memahami peran dan tanggung jawab bisnisnya dengan baik dan mampu menunjukkan kreatifitas dan inovasi guna mendukung dan mempercepat keberhasilan. Keempat, menyampaikan konteks bisnis dalam bidang edukasi dan mampu mengomunikasikan lembaganya dengan strategi yang tepat. Membayar gaji karyawan tepat waktu dan sesuai dengan pekerjaanya yang dapat mencukupi kebutuhan hidup mereka dan dapat menjadi motivasi untuk meningkatkan kinerja seorang karyawan. Serta dapat memberikan pembinaan terhadap staff dan masyarakat secara gratis tanpa ada income.

\section{DAFTAR PUSTAKA}

Aditama, Dewantara, (2020) Etika Distribusi Ekonomi Islam (Perbandingan Sistem Distribusi Kapitalis Dengan Sistem Distribusi Islam). Ad Deenar: Jurnal Ekonomi Dan Bisnis Islam, 2020, 4.01.

Angkita, Mulyawisdawati Richa, (2019). Implementasi Etika Bisnis Islam di CV

Rumah Warna Yogyakarta. Ijtihad: Jurnal Hukum dan Ekonomi Islam, 13.2.

Ayu, Mardasari Leka. Strategi Pemasaran Dalam Pengembangan Usaha Pada Konveksi Wijaya Di Desa Botoran Tulungagung Perspektif Ekonomi Islam. Eksyar: Jurnal Ekonomi Syari'ah \& Bisnis Islam, 2020, 7.02.

Aziz, Abdul, (2013). Etika Bisnis Perspektif Islam, Bandung : Alfabeta.

Barqi, Yahya Aqil, (2020). Etika Bisnis (Perilaku) Bisnis Rasulullah Saw Sebagai

Pedoman Berwirausaha. Jurnal Masharif Al-Syariah: Jurnal Ekonomi Dan Perbankan Syariah, 5.1.

Bayu, Kurniawan Dwiatma, (2019). Etika Bisnis Islam Dalam Pelayanan Haji Dan Umroh. Bina'al-Ummah, 14.1.

Bukhari, Alma, (2009). Manajemen Bisnis Syariah, Bandung: Alfabeta. 
Elfi, Barus Elida dan Nuriani, Nuriani, (2016). Implementasi Etika Bisnis Islam (Studi Pada Rumah Makan Wong Solo Medan). Jurnal Perspektif Ekonomi Darussalam, 2.2.

Fitri, Amalia, (2012). Implementasi Etika Bisnis Islam Pada Pedagang Di Bazar Madinah Depok. Prosiding Seminas), 1.2.

G.Webster, (1980). Webster's New Collgiatem Dictionary, New York : G.C.Merriam Company.

Haris, Faulidi, Gusriani, Raden Yani, (2017). Dakwah Dalam Bisnis Dan Enterpreneur Nabi Muhammad SAW. Alhadharah: Jurnal Ilmu Dakwah, , 11.21.

Hasan, Ali, (2009). Manajemen Bisnis Syari'ah Kaya di Dunia Terhormat di Akhirat, Yogyakarta: Pustakan Pelajar.

Kurniawan, Dwiatma Bayu, (2019). Etika Bisnis Islam Dalam Pelayanan Haji Dan Umroh. (Bina'al-Ummah), 14.1.

Rosiyana, Leli Arifin, Zainul, dan Sunarti, Sunarti, (2017). Implementasi Etika Bisnis

Islam Guna Membangun Bisnis Yang Islami (Studi pada Waroeng Steak And Shake Cabang Malang). Jurnal Administrasi Bisnis, 53.1.

Saifullah, Muhammad, (2011). Etika Bisnis Islami Dalam Praktek Bisnis Rasulullah Walisongo Jurnal Penelitian Sosial Keagamaan, 19.1.

Yani, Raden Gusriani, Faulidi, Haris, (2017). Dakwah Dalam Bisnis Dan Enterpreneur Nabi Muhammad SAW. Alhadharah: Jurnal Ilmu Dakwah, 11.21. Zubair, Achmad Charris, (1995). Kuliah Etika, Jakarta : Rajawali Press. 